\title{
Off-gas emission response mechanism in aerobic composting of sewage sludge: A review
}

\author{
Yulan $\mathrm{Lu}^{1,2,3}$, Yu Dai ${ }^{1,2,3}$, Haiguang Qin ${ }^{1,2,3}$, Jun $\mathrm{Li}^{1,2,3}$, and Jun Zhang ${ }^{1,2,3,}$ * \\ ${ }^{1}$ Guangxi Key Laboratory of Environmental Pollution Control Theory and Technology, Guilin University of Technology, Guilin \\ 541004, China. \\ ${ }^{2}$ Collaborative Innovation Center for Water Pollution Control and Water Safety in Karst Area, Guilin University of Technology, \\ Guilin 541004, China. \\ ${ }^{3}$ College of Environmental Science and Engineering, Guilin University of Technology, Guilin 541004, China
}

\begin{abstract}
In recent years, sludge output has increased rapidly with the dramatical growth of sewage treatment capacity. As a typical technology to treat organic solid waste, composting combined with land utilization is a wide-used to deal with sewage sludge. However, the off-gas emission, which includes odors and greenhouse gas, still is a ubiquitous problem in the composting industry. In this study, we reviewed the findings about this topic in the last decades. It was summarized that what was the emission mechanism of off gas and which are the key factors during aerobic composting of sewage sludge. The off-gas emission is corresponding to the anaerobic-region distribution in matrix, which is intensively affected by the obstructed gas region in matrix and physicochemical properties of the matrix particle. And some suggestions and prospects for future research are put forward to provide a reference for solving the off-gas emission problem of aerobic composting of sewage sludge in China.
\end{abstract}

\section{Introduction}

Sewage sludge is a typical organic solid waste in China. With the rapid increase of urbanization, Chinese sewage discharge has also risen stably, from 52.45 billion ton in 2005 to 71.62 billion ton in 2014. However, the amount of sewage sludge rises stably during sewage treatment, which output has exceeded 30 million tons (moisture content $80 \%$ ). Most of the sludge is lack of resource treatment measures, only a small part of which is returned to the field as compost fertilizer and most of it is directly dumped and stacked, which not only causes nutrient loss, but also causes serious pollution to the rural soil, atmosphere, water body and biology [1]. During the composting process, the components of the raw material contribute to the production of volatile organic compounds (VOCs) and the emission of odors, which releases a large number of unpleasant odors in the openair system. However, odor pollution has become an obstacle to the promotion of composting technology to treat industrial sewage sludge [2]. The production of odor not only affects the normal life of human beings and interferes with the social welfare of surrounding areas, but also may cause a hazard to human health[3]. After composting, sludge has the characteristics of water and fertilizer retention, enhanced soil nutrients, and improved soil properties. Despite the advantages of hygienization and recycling, there are still some problems in the emission of odor and greenhouse gas in aerobic composting.

In order to further understand the current off-gas emissions response mechanism during aerobic composting of sewage sludge. We will review aerobic composting of sewage sludge off-gas emissions research progress on the basis of the response mechanism, clarify the response mechanism of the anaerobic region of off-gas emissions, explore the optimal operation for the reduction of hazardous off-gas emission, and then discuss the anaerobic region of some shortcomings, we put forward ideas and suggestions of off-gas emission response mechanism during aerobic composting of sewage sludge.

\section{Off-gas emission during aerobic composting}

The emission of large amounts of odor and greenhouse gas has caused serious environmental problems. In the process of sludge composting, a large amount of harmful odor was produced in the composting plant, which caused serious environmental pollution and environmental safety problems, and had a very impact on the urban sanitation environment and the daily life of residents. A large quantity of the harmful odor was produced in the composting on the composting plant, which caused serious environmental pollution and safety problems, had a very bad impact on the urban sanitation environment and the daily life of residents. As a result, the composting plant was complained by local people and could not operate normally. Aerobic composting is an effective method for the recycling, harmlessness and reduction of sewage sludge. While a large amount of gaseous pollutants such

\footnotetext{
${ }^{\text {*Corresponding author: zjun@glut.edu.cn }}$
} 
as odor and greenhouse gas are generated during the composting process. Among them, the primary odors discharged by the matrix are $\mathrm{NH}_{3}$ and sulfur-containing volatile substances, and the main greenhouse gases are $\mathrm{CH}_{4}, \mathrm{~N}_{2} \mathrm{O}$.

\subsection{Odor}

The main pollutants of sulfur-containing odor are different from different material sources. Approximately 80 types of substances were detected, including 2 volatile inorganic compounds, 4 sulfur organic compounds, 16 benzenes, 27 alkanes, 15 alkenes, and 19 halogenated compounds (Table 1), of which inorganic and organic sulfur compounds account for about $80 \%$ of the total odor pollutants [4]. In general, high-nitrogen materials tend to release more $\mathrm{NH}_{3}$ in the process of biodegradation [5], while sulfur volatile organic compounds are an significant source of odor, which should be emphatically controlled[4].

Table 1 Odor composition during sewage sludge composting [4].

\begin{tabular}{clc}
\hline Chemical compound & \multicolumn{1}{c}{ Pollutants } & Species \\
\hline $\begin{array}{c}\text { Volatile inorganic } \\
\text { compounds }\end{array}$ & Hydrogen sulfide, ammonia & 2 \\
$\begin{array}{c}\text { Sulfur organic } \\
\text { compounds }\end{array}$ & Methyl mercaptan, dimethyl sulfide, dimethyl disulfide, carbon disulfide & 4 \\
Benzenes & $\begin{array}{l}\text { Benzene, toluene, ethylbenzene, dimethylbenzene, p-xylene, isopropylbenzene, } \\
\text { propylbenzene, m-ethyltoluene, m-xylene, 1,3,5-trimethylbenzene, o-ethyltoluene, }\end{array}$ & 16 \\
& $\begin{array}{l}1,2,4-\text { trimethylbenzene, 1,2,3-trimethylbenzene, 1,2-diethylbenzene, 1,4- } \\
\text { thylbenzene, styrene } \quad\end{array}$ \\
\hline
\end{tabular}

Continued Table 1 Odor composition during sewage sludge composting [4].

\begin{tabular}{|c|c|c|}
\hline Chemical compound & Pollutants & Species \\
\hline Alkanes & $\begin{array}{l}\text { Isobutane, butane, isopentane, pentane, 2,2-dimethyl-butane, cyclopentane, 2,3- } \\
\text { dimethyl-butane, 2-methyl-pentane, 3-methyl-pentane, n-hexane, } \\
\text { methylcyclopentane, 2,4-dimethyl-pentane, cyclohexane, 2-methyl-hexane, 2,3- } \\
\text { dimethyl-pentane, 3-methyl-hexane, 2,2.4-trimethyl-pentane, heptane, } \\
\text { methylcyclohexane, 2,3,4-trimethyl-pentane, 2methyl-heptane, 3-methyl-heptane, n- } \\
\text { octane, nonane, decane, undecane, dodecane }\end{array}$ & 27 \\
\hline Alkenes & $\begin{array}{l}\text { 1-Butene, 1,3-butadiene, t-2-butene, c-2-butene, 3-methyl-1-butene, 1-pentene, } \\
\text { isoprene, t-2-pentene, c-2-pentene, 2-methy-2-butene, cyclopentene, 4-methyl-1- } \\
\text { pentene, 1-hexene, t-2-hexene, c-2-hexene }\end{array}$ & 15 \\
\hline $\begin{array}{l}\text { Halogenated } \\
\text { compounds }\end{array}$ & $\begin{array}{l}\text { Freon-12, dichloromethane, Freon-114, vinyl-chloridev, chloroethane, freon 11, 1,1- } \\
\text { dichloro-ethene, 1,1-dichloroethane, Freon-113, 1,1-dichloro-ethane, 1,2- } \\
\text { dichloroethene (E), chloroform, 1,2-dichloroethane, carbon tetrachloride, 1,2- } \\
\text { dichloro-propane, trichloroethane, chlorobenzene, 1,2-dichloro-benzene, 1,3- } \\
\text { dichloro-benzene }\end{array}$ & 19 \\
\hline
\end{tabular}

\subsection{Greenhouse gas}

Currently, high-temperature aerobic composting is a common sludge stabilization technology. However, a large number of greenhouse gas will be generated in the composting, which will not only cause nitrogen loss and decrease the fertilizer efficiency of composting products but also contribute to the greenhouse effect. In the organic solid waste aerobic composting process, $\mathrm{N}_{2} \mathrm{O}$ and $\mathrm{CH}_{4}$ are the main greenhouse gas emitted during the composting. The 100-year greenhouse effect of these two gases is 298 times and 25 times that of equimolar $\mathrm{CO}_{2}$, and their emissions make up $0.02 \% \sim 0.7 \%$ of total nitrogen and $0.05 \% \sim 3 \%$ of total carbon in the raw material $[6,7] . \mathrm{N}_{2} \mathrm{O}$ is also believed to damage the ozone layer, so these gas emissions must be mitigated (Table 2).

Table 2. Greenhouse gas emissions from aerobic composting of sewage sludge [8].

\begin{tabular}{|c|c|c|c|}
\hline Compost material & $\begin{array}{c}\text { Cumulative } \mathrm{CO}_{2} \\
\text { production }\left(\mathrm{g} \cdot \mathrm{kg}^{-1} \mathrm{TC}\right)\end{array}$ & $\begin{array}{c}\text { Cumulative } \mathrm{CH}_{4} \\
\text { production }\left(\mathrm{g} \cdot \mathrm{kg}^{-1} \mathrm{TC}\right)\end{array}$ & $\begin{array}{c}\text { Cumulative } \mathrm{N}_{2} \mathrm{O} \\
\text { production }\left(\mathrm{g} \cdot \mathrm{kg}^{-1} \mathrm{TC}\right)\end{array}$ \\
\hline sludge + straw & 407 & - & 10.2 \\
\hline sludge + Sawdust & 364 & 0.5 & 7.7 \\
\hline sludge + beet molasses & 426 & 0.2 & 12 \\
\hline sludge + wheat straw & 407 & 0.6 & 8.7 \\
\hline
\end{tabular}




\section{Off-gas emission mechanism and factors}

\subsection{Greenhouse gas}

\subsubsection{Emission mechanism}

The anaerobic microenvironment, which is formed by the partial $\mathrm{O}_{2}$ deficiency in the matrix particles, is called the anaerobic region, which is the primary mechanism leading to the generation of greenhouse gas during the composting process [9]. Nitrification - denitrification is the main way to produce $\mathrm{N}_{2} \mathrm{O}$ in the matrix, which generally occurs during the rapid heating and cooling periods of composting [10,11], and its reaction intensity is affected by the distribution of anaerobic regions in matrix particles. The emission of $\mathrm{CH}_{4}$ mainly occurs during the rapid heating period of aerobic composting. At this stage, microorganisms quickly decompose easily degradable organic substances and consume a large amount of $\mathrm{O}_{2}$, resulting in a large number of anaerobic regions inside the particles, which causes anaerobic bacteria to decompose some organic substances to produce $\mathrm{CH}_{4}$ [12].

\subsubsection{Factors}

The emission of greenhouse gas in the composting process is connected with many factors, such as $\mathrm{C} / \mathrm{N}$ ratio, ventilation conditions, temperature, moisture content. Since $\mathrm{N}_{2} \mathrm{O}$ is mainly derived from the denitrification reaction inside the matrix, it accounts for the primary component of the greenhouse gas emitted during the composting process. When there are sufficient and available carbon sources in the matrix, the heterotrophic denitrification bacteria grow and reproduce rapidly, which promote the process of denitrification producing $\mathrm{N}_{2} \mathrm{O}$. However, the lower $\mathrm{C} / \mathrm{N}$ ratio reduces the air space and increases the readily available carbon sources, which leads to insufficient oxygen supply for the matrix, and methanogens produce higher $\mathrm{CH}_{4}$ under anaerobic conditions [13]. The ventilation mode of compost regulates the distribution pattern of oxygen and affects the greenhouse gas emission in the composting process. The impact of forced ventilation on the greenhouse gas emissions in the composting process depends on the amount of ventilation. When the amount of ventilation is low, there is a partial anaerobic environment in the matrix, which is conducive to the denitrification to produce a large quantity of $\mathrm{N}_{2} \mathrm{O}$. The emission of $\mathrm{CH}_{4}$ is increased when the carbon forms $\mathrm{CH}_{4}$ through the action of anaerobic bacteria.

While the ventilation is high, nitrogen is lost in the form of $\mathrm{NH}_{3}$ in the early stage of composting, reducing $\mathrm{N}_{2} \mathrm{O}$ emissions in the entire composting process [10]. In the early stage of composting, the emission fluxes of $\mathrm{CH}_{4}$ and $\mathrm{N}_{2} \mathrm{O}$ were both high and decreased with the increase of moisture content [14]. In the aerobic composting of sewage sludge, it is easy to form anoxic state for the moisture content of composting material remains above $50 \% \mathrm{~N}_{2}$ is mainly generated by denitrification in the material, which inhibits the production of $\mathrm{N}_{2} \mathrm{O}$ in the composting process [10]. However, when the moisture content decreased to $13 \% \sim 44 \%$, methanotroph were inhibited, $\mathrm{CH}_{4}$ emission flux increased and $\mathrm{N}_{2} \mathrm{O}$ emission was restrained.

\subsection{Harmful gas}

\subsubsection{Emission mechanism}

The odorous gas emitted during sludge composting are usually $\mathrm{NH}_{3}$ and volatile sulfur compounds (VSCs) [1518]. In the initial stage of composting, organic substances that are easy to decompose are fast decomposed (usually reaching the decomposition peak within 3 days), which consumes a large amount of oxygen, it causes partial hypoxia and produces a large number of VSCs in the matrix, and also produces a small amount of organic acids and $\mathrm{NH}_{3} . \mathrm{NH}_{3}$ emissions are affected by the $\mathrm{NH}_{4}{ }^{+}$content of the material. Due to the high temperature characteristics of the matrix and the high temperature period is the primary period of ammonia volatilization during the composting process. The $\mathrm{NH}_{4}{ }^{+}$content of the material decreases because of $\mathrm{NH}_{3}$ volatilization and $\mathrm{NH}_{4}^{+}$ assimilation and nitrification after entering the maturity period, and ammonia volatilization is also significantly reduced. Poor $\mathrm{O}_{2}$ transport due to insufficient aeration has been considered to be the main reason of malodorous gas during aerobic composting of sewage sludge, and VSCs are the primary source of composting malodors. It is generally believed that VSCs are released from organic compounds during anaerobic, exothermic or incomplete aerobic fermentation, even VSCs can be emitted into the atmosphere under aerobic conditions [19].

\subsubsection{Factors}

The emission of harmful gas in composting process is related to many factors, such as $\mathrm{C} / \mathrm{N}$ ratio, ventilation rate, moisture content, conditioner. $\mathrm{NH}_{3}$ is generated by the decomposition of nitrogenous substances (namely proteins and amino acids), which often occurs in the discharge stage thermophilic aerobic decomposition, and tends to be high emission in the case of low $\mathrm{C} / \mathrm{N}$ ratio [20]. It is commonly believed that the lower the $\mathrm{C} / \mathrm{N}$ ratio of compost, the more serious ammonia volatilization [21]. Reducing ventilation can bring about insufficient supply of $\mathrm{O}_{2}$ locally in the matrix, while too high will lead to evaporate of ammonia in the composting. Relevant research shows that the generation of $\mathrm{H}_{2} \mathrm{~S}$ can be controlled as long as the oxygen content of the stack is higher than $14 \%$ [18].

In addition, inadequate ventilation has always been considered as a major factor in the production of VSCs. It is generally believed that VSCs are mainly produced under anaerobic conditions or incomplete aerobic fermentation conditions $[19,22]$. High moisture content can reduce the mass transfer efficiency of $\mathrm{O}_{2}$, leading to a large number of anaerobic regions of reactor particles and promoting the generation and release of odor [23]. Excessive moisture content will plug up the pores in the material. It leads to 
the emergence of the anaerobic environment, which against the growth and reproduction of aerobic microorganisms, resulting in a large amount of odor because of the anaerobic decomposition of organic substances. Increasing the moisture content of materials will cause more water entering the pores inside the matrix, which reduce the diffusion of oxygen between aggregates, weaken the mineralization of organic nitrogen, and thus reduce ammonia volatilization in the composting process. The difference of the conditioner can affect the $\mathrm{C} / \mathrm{N}$ ratio, moisture content and porosity of the material, thus affecting the mass transfer and consumption of $\mathrm{O}_{2}$, organic transformation pathway and the generation and release of odor [24].Conditioners are organic substances added to composted materials in the composting. Since it can increase the amount of degradable organic substances in the material, improve the material structure, and magnify the area in contact with the air, so can adjust the $\mathrm{C} / \mathrm{N}$ ratio and moisture content of the whole composting process, and also play a key role in deodorization.

\subsection{The effect of anaerobic region on harmful off- gas emission}

The generation and release of odor is affected by the concentration distribution of $\mathrm{O}_{2}$ in the matrix particles, which mainly occurs in the rapid heating period of the stack. The existence of anaerobic region is a prerequisite for the discharge of sulfur-containing odor in the composting process. Nitrification - denitrification is the major way to produce $\mathrm{N}_{2} \mathrm{O}$ in the matrix [15], and its reaction intensity is affected by the distribution of the anaerobic region in matrix particles. $\mathrm{CH}_{4}$ emission mainly occurs in the rapid heating period of aerobic composting, during which microorganisms promptly decompose readily degradable organic substances and consume a large amount of $\mathrm{O}_{2}$, leading to the emergence of a large number of anaerobic areas inside the particles, which causes anaerobic bacteria to decompose some organic substances and produce $\mathrm{CH}_{4}[3]$.

\section{Anaerobic region of matrix}

\subsection{Anaerobic region in the particle}

The distribution of the anaerobic region in matrix particles is controlled by the processes of ventilation supply, oxygen mass transfer, microbial consumption and particle adsorption. Due to the combined effect of $\mathrm{O}_{2}$ mass transfer resistance, microbial consumption and adsorption, a gradient of dissolved oxygen concentration is formed inside matrix particles. When the ventilation supply is sufficient, the $\mathrm{O}_{2}$ concentration on the surface of the particles is high, but there may still be anaerobic region inside the particles of the larger particle size. Conversely, the concentration of $\mathrm{O}_{2}$ on the surface of the particles decreases, and the range of the anaerobic region inside the particle expands accordingly. The material of the matrix has the characteristics of porous media. The partial matrix is blocked by convection and mass transfer to form the obstructed gas region, which reduces the efficiency of convection/diffusion oxygen supply, reduces the $\mathrm{O}_{2}$ concentration on the surface of the particles, and expands the range of anaerobic areas inside the particles.

At present, the research on anaerobic composting is based on the overall oxygen mass balance, and only a few studies involve the distribution characteristics of the anaerobic region in the particle. And in the anaerobic research of traditional anaerobic composting, the onedimensional convection-reaction model is mostly used [25], which assumes the $\mathrm{O}_{2}$ concentration in the matrix is evenly distributed along the ventilation direction along the various sections to predict whether the matrix is anaerobic as a whole. It is impossible to describe and predict the distribution range and influence of the anaerobic region inside the particles. In order to make up for the deficiencies of the above research, Hameler uses the Gamma function to describe the particles size distribution of the material on the basis of assuming that the matrix is generally uniform, which proposes the hypothesis of aerobic-anaerobic double-layer structure of particles based on gas diffusion, and analyzes the effect of anaerobic region in the particle during the composting [26]. This hypothesis was perfected by Ge et al. [27] that combines with the developed micro-FTIR(Fourier Transform infrared spectroscopy) for indirectly measuring the thickness of the aerobic layer of particles, which characterizes the dynamic thickness of the aerobic layer during aerobic composting, establishing the temporal variation model of the anaerobic region distribution in matrix particles, and it was used to predict the oxygen consumption rate of materials and $\mathrm{CH}_{4}$ emissions during the aerobic composting process of pig manure [28, 29].

\subsection{Obstructed gas region}

There is mutual squeezing and stacking between the material particles, so that a large number of closed or semiclosed pores are generated locally in the matrix, which form a micro obstructed gas region. For the intermittent ventilation pattern widely used in the composting project, the voids in the matrix are in the non-ventilated state during the stopping aeration period of the ventilation cycle. It can be considered that the anaerobic region in the particle expands to all voids, forming the obstructed gas region. Among them, the obstructed gas region in matrix is in a partial and overall periodic alternation in the intermittent ventilation composting process, which has a strong influence on the distribution of the anaerobic region in the particle. Part of the $\mathrm{O}_{2}$ in the obstructed gas region is adsorbed on the surface of the particles and part of it diffuses into the the liquid phase of the particles, which is quickly consumed by microorganisms. It is difficult to be quickly replenished by air convection, making the $\mathrm{O}_{2}$ concentration on the surface of the particle lower than the air flow region, expanding the existence and influence of the anaerobic region in the particle. And the change in the distribution of the anaerobic region in the particle also in turn affects the rate of microbial consumption of $\mathrm{O}_{2}$, forming a coupling relationship between the obstructed gas region and the distribution of the anaerobic region in the particle, thereby changing the internal odor generation 
and release characteristics in the matrix particles.

There are still few research reports related to this aspect. Only Huet et al. [30] conducted a preliminary exploration on the phenomenon that the free space of the reactor material and the gas permeability are affected by the compaction, but did not conduct an in-depth study on the characteristics of the obstructed gas region and its impact on the law of off-gas emissions. This is related to the lack of research methods for the characteristics of the obstructed gas region in the matrix and the distribution of anaerobic region in the particle.

\section{Conclusions and prospects}

The main factors that affect the characteristics of the obstructed gas region include temperature, moisture content, particle size distribution and compaction, which can affect the internal and external gas exchange coefficients, pore structure and boundary range of the obstructed region, respectively. Therefore, when studying the impact of the anaerobic region in matrix particles on odor emissions, it is necessary to clarify the characteristics of the obstructed gas region and its coupling relationship with the distribution of the anaerobic region in matrix particles. However, for the gas tracing experiment, which is a key step in parameter inversion of the obstructed gas region, no tracing conditions suitable for composting materials have been established.

There are still few research reports on this aspect, and more work needs to be done. It is recommended to conduct research from the following aspects: (1) developing a new analysis method through measuring the obstructed gas region by estimating parameters from pulse gas tracer experiments, and lay the foundation for the study of the method of the gas pulse tracing to retrieve the characteristic parameters of the obstructed gas region in matrix; (2) identifying the key environmental factors which affect the distribution characteristics of obstructed gas region in matrix; (3) elucidating the response mechanism of the off-gas emission to the obstructed gas region on the basis of the coupling relationship between the obstructed gas region and anaerobic region in the particle.

\section{References}

1. M.B. J. Lopez-Real. COMPOST SCI UTIL 4, 7182 (1996)

2. Andersson, Maria, J., E., Linus, Bende, et al. OCCUP ENVIRON MED 51:, 835-847 (2009)

3. M.C. Gutiérrez, J.A. Siles, J. Diz, A.F. Chica, M.A. Martín. Waste Manage. 59, 48-58 (2016)

4. Y.L. Zhu, G.D. Zheng, G. Ding, T.B. Chen, F.K. Wu, M.J. Niu, et al. Air Waste Manage. Assoc. 66, 930940 (2016)

5. S.B. Abebe Nigussie, Thomas W. Kuyper, Andreas de
Neergaard. Chemosphere 166, 352-362 (2017)

6. K.M.D.H.R.M.S.T.N.Y.a.T. Osada. Soil Sci. Plant Nutr. 59, 96-106 (2013)

7. X. Hao, C. Chang, F.J. Larney. J. Environ. Qual. 33, 37-44 (2004)

8. J.M. Paillat, P. Robin, M. Hassouna, P. Leterme. Atmospheric Environ. 39, p.6833-6842 (2005)

9. M.C. Gutierrez, J.A. Siles, J. Diz, A.F. Chica, M.A. Martin. Waste Manage. 59, 48-58 (2017)

10. W. Wu, L. Li, H. Lv, C. Wang, H. Deng. J Appl Ecol 23, 1704-1712 (2012)

11. G.L. Tao Jiang, Qiong Tang. J Environ Sci(China) 31:, 124-132 (2015)

12. C. Zhao, Y. Wei, Z. Ge, Z. Jia, X. Cai, Y. Zhang, et al. Eenvironmental Science 035, 2798-2806 (2014)

13. F.S. Tao Jiang, G.X. Li. J Environ Sci (China) 23, 1754-1760 (2011)

14. Y. Fukumoto, T. Osada, H. Dai, K. Haga. Bioresour. Technol. 89, 109-114 (2003)

15. C. Maulini Duran, A. Artola, X. Font, A. Sánchez. Bioresour. Technol. 147, 43-51 (2013)

16. E. Pagans, Barrena, R., Font, X., Sánchez, A. Chemosphere 62, 1534-1542 (2006)

17. A. Zigmontiene, E. Zuokaite. J ENVIRON ENG LANDSC 18, 128-136 (2010)

18. J. Chen, T.B. Chen, G. Ding, L. Mei, G.D. Zheng, H.T. Liu, et al. Waste Manage. 31, 65-70 (2011)

19. H. Zhang, F. Schuchardt, G. Li, J. Yang, Q. Yang. Waste Manage. 33, 957-963 (2013)

20. Y. Liang, J.J. Leonard, J.J.R. Feddes, W.B. Mcgill. Bioresour. Technol. 97, 748-761 (2006)

21. G.F. Huang, J.W.C. Wong, Q.T. Wu, B.B. Nagar. Waste. Manage. 24, 805-813 (2004)

22. T.J. He P, Zhang D, et al. J Environ Sci (China) 116123 (2010)

23. B. Zang, S. Li, F.M. Jr., G. Li, Y. Luo, D. Zhang, et al. Waste Manage. 56, 498-505 (2016)

24. V. Blazy, A.D. Guardia, J.C. Benoist, M. Daumoin, M. Lemasle, D. Wolbert, et al. Waste Manage. 34, 1125-1138 (2014)

25. J.F. Zeng, X.L. Shen, L.J. Han, G.Q. Huang. Bioresour. Technol. 220, 104-109 (2016)

26. H.H.V. M. Environ. Sci. Technol. 3, 331-342 (2004)

27. Jinyi, Ge, Guangqun, Huang, Zengling, Yang. Environ. Sci. Technol. 48, 5043-5050 (2014)

28. J.Y. Ge, G.Q Huang, J. Huang, J.F. Zeng, L.J. Han. CHEM ENG J 22, 752-760 (2015)

29. J.Y. Ge, G.Q Huang, J. Huang, J.F. Zeng, L.J. Han. Environ. Sci. Technol. 50, 4374-4383. (2016)

30. J. Huet, C. Druilhe, A. Trémier, J.C. Benoist, G. Debenest. Bioresour. Technol. 114, 428-436 (2012) 